\title{
LA JUSTICIA EN LAS ALJAMAS CASTELLANAS A FINES DEL SIGLO XV: LA FRONTERA ORIENTAL DEL REINO DE CASTILLA
}

ENRIQUE CANTERA MONTENEGRO

Universidad Nacional de Educación a Distancia

\section{Planteamiento general}

A lo largo de la Edad Media, las comunidades judías distribuidas por las diferentes regiones europeas se esforzaron por mantener el principio de la autonomía judicial. Las competencias de los dirigentes de las aljamas no se limitaban exclusivamente a los asuntos comunales más corrientes; por el contrario, de los "mukadenim» (adelantados), "dayyanim» (jueces) y "albendín" o "vedì (alguaciles) dependía también la vigilancia acerca del cumplimiento de la moral y de la religión judías, la persecución de los malhechores y la defensa de la comunidad frente a los malsines, aspectos todos ellos vitales para la conservación de la minoría judía y de su religión en el seno de la sociedad cristiana.

El principio general que regía la autonomía judicial de las comunidades judías es que ningún miembro de ellas debía acudir a un tribunal de justicia no judío. Maimónides (Hilkôt Sanhedrín 26,7) consideraba que no respetar este principio constituía una profanación, incluso en el caso de que existiera una coincidencia con las leyes judías. Otros autores interpretaban la sentencia bíblica: «Éstos son los juicios que pondrás ante ellos» (Ex 21,1) en el sentido de que no sólo el Derecho de los pueblos gentiles era distinto de la Halaka o Derecho judío sino que, incluso, legítimamente se infería que no estaba permitido acudir a sus tribunales de justicia 1

Es comúnmente aceptado que en materia judicial y penal la autonomía de que disfrutaron las aljamas hispanas fue muy superior

${ }^{1}$ F. Diaz Esteban, *Aspectos de la convivencia jurídica desde el punto de vista judio en la España medieval», en Actas del II Congreso Internacional Encuentro de las Tres Culturas, Toledo 1985, págs. 105-116. (Véase pág. 111). 
con relación a la de sus correligionarios de otros países europeos, lo que es muy probable que tenga sus raíces en la España musulmana; no en vano, en determinados momentos los judíos andalusíes contaron con autorización para juzgar en materia penal.

La jurisdicción penal de los judíos hispanos fue extraordinariamente amplia a lo largo de toda la Edad Media - de manera muy particular en el reino de Castilla ${ }^{2}-$, y con ella los judíos persiguieron en todo momento un doble objetivo: velar por la disciplina religiosa y moral, y afirmar la autodefensa político-nacional frente a los malsines. Las aljamas judías castellanas recibieron sus derechos en materia de jurisdicción penal de forma paralela al desarrollo de las atribuciones judiciales de los municipios ${ }^{3}$.

Aunque en algunas comunidades era el propio Consejo quien entendía en las causas procesales, lo más habitual era la existencia de una corte de justicia elegida por la propia comunidad, o por el Consejo, por un período limitado de tiempo, generalmente un año. Pese a que el número variaba de unas comunidades a otras, lo más usual era la corte de tres jueces o "dayyanim", entre los que siempre figuraba el rabino principal. Cualquier resolución del tribunal local de justicia podía ser apelada ante el Rabí Mayor.

Las facultades concedidas a las aljamas para juzgar sus causas penales alcanzaron su mayor amplitud en la Corona de Castilla en el siglo XIV. Los jueces judíos de Castilla juzgaban los pleitos penales relativos a los malsines, así como los casos de asesinato, violación o adulterio, e imponían penas que contemplaban la mutilación, el destierro e, incluso, la muerte.

La documentación jurídica ${ }^{4}$ refleja también otros castigos duros, aunque no sangrientos, establecidos por la legislación judía castellana por el incumplimiento de distintos preceptos religiosos, como los relativos al Sabbat, a la purificación ritual, a las prescripciones alimenticias, a la obligación de enseñar la Torá a los niños, o por el incumplimiento de los contratos económicos.

El rigor de los castigos no es extraordinario, sino que se encuen-

${ }^{2}$ En la Corona de Aragón las sentencias de los jueces judíos debían ser confirmadas por el Consejo Real o por la Curia, de forma previa a su ejecución.

${ }^{3}$ Y. BAER, Historia de los Judlos en la Espanta Cristiana, Madrid 1981, 2 vols. (Véase vol I, pág. 185).

4 Por ejemplo el Libro de los Fueros de Castilla, que recoge algunas noticias sobre las prácticas jurídicas de los judíos castellanos, centradas especialmente en la comunidad de Burgos. 
tra en línea con la legislación europea medieval, y fue de capital importancia para la conservación del judaísmo, porque velaba por el mantenimiento de la cohesión interna de la comunidad, fundamental para todo colectivo humano minoritario integrado en una sociedad mayoritaria.

La ejecución de las sentencias de los "dayyanim" recaía en los oficiales reales quienes, normalmente, no ponían ningún impedimento para ejecularlas, pues era una forma de garantizar el orden y la disciplina en el interior de las aljamas. Es el mismo motivo por el que los órganos de la administración central solían ratificar siempre los acuerdos de los «mukadenim».

Hasta 1380 los jueces judíos tenían autoridad para condenar a muerte a los malsines y para obligar a los oficiales reales a ejecutar esta sentencia, previo pago por parte de la aljama de la caloña correspondiente a la víctima, pues no hemos de olvidar que los judíos eran vasallos directos del monarca s.

Sin embargo, en las Cortes de Soria de 1380 el rey Juan I de Castilla, utilizando probablemente como argumento la muerte de Yosef Pichó, quien fuera tesorero de Enrique II -acusado de malsín por los jueces judíos de Burgos - suprimió definitivamente este privilegio. En adelante, los judíos no podrían juzgar ningún pleito penal que supusiera «muerte de omne o perdimiento de miembro o desterramiento». Sólo quedaban autorizados a juzgar pleitos civiles internos y a elegir uno de los jueces cristianos del lugar para que librara sus pleitos criminales. En cualquier caso, la sentencia del juez podía ser apelada ante la justicia real ${ }^{6}$.

Las Leyes de Ayllón, promulgadas el 2 de enero de 1412 durante la regencia de la reina doña Catalina de Lancaster, van aún más lejos al prohibir que los jueces judíos juzguen todo tipo de causas, tanto civiles como criminales. Entre las diversas disposiciones limitativas de la autonomía de las aljamas, en su artículo séptimo establecen lo siguiente:

${ }^{5}$ L. SuÁrez Fernández, Judios españoles en la Edad Media, Madrid 1980. (Véase pág. 107).

- Parecido proceso se siguió en la Corona de Aragón: tres años antes, en 1377, el rey Pedro IV de Aragón había acordado que las sentencias de pena de muerte y de mutilación se sustrajeran del tribunal judío de Barcelona. Así mismo, los delitos referentes al mercado pasaban a la jurisdicción del «mustaçaf", un funcionario concejil. Por el contrario, continúan siendo competencia del tribunal judío los delitos de fornicación de judío con cristiana y de judío con judía, así como el de malsindad. 
"Otrosí: Que las aljamas de los judíos e moros de los mis regnos e señoríos non puedan aver nin ayan daquí adelante jueçes judíos nin moros entre sí, porque les libren sus pleytos, asy çeviles como criminales, que acaesçen entre judíos e moros e moras; e revócoles qualquier poderío que de mí e de los reyes, mis anteçesores, tienen en la dicha raçón, por privilegio e en otra manera, e dólo por ninguno; e mando que sean librados daquí adelante los tales pleytos, asy criminales como çeviles, de entre los dichos judíos, e judías, moros e moras, por los alcaldes de las çibdades e villas e logares donde moraren. Pero es mi merçed que los tales alcaldes guarden, en el libramiento de los pleytos çeviles, las costumbres e ordenanzas que fasta agora guardaron entre si los tales judíos e moros, tanto que parezcan auténticas e aprovadas por ellos de luengo tiempo acá».

Todo hace suponer que estas leyes no fueron llevadas a la práctica con rigor, pero desde este momento quedaba al arbitrio de los concejos el grado de aplicación de las mismas, lo que suponía un peligro en potencia para la comunidad hebrea. Al mismo tiempo, son un claro indicativo de la decidida voluntad de los órganos de gobierno centrales de poner coto a la autonomía judicial de las comunidades judía y múdejar.

Veinte años después, y bajo la dirección de Abraham Bienveniste, Rabí Mayor de los judíos de Castilla, representantes de todas las aljamas del reino y algunos judíos de la Corte, reunidos en Valladolid, procedieron a la redacción de los Estatutos o Taqqanót que, en adelante, habrían de servir como norma de gobierno para todas las comunidades hebreas castellanas.

Uno de los objetivos de estos Estatutos es asegurar la plena autonomía judicial de la comunidad judía, en entredicho desde la promulgación de las leyes de Ayllón. El segundo capítulo de las Taqqanót se refiere a la elección de los cargos de gobierno de la aljama y, en concreto, de los jueces. Como se comprobó que había bastantes aljamas que no tenían jueces, se dio un plazo de diez días para que todas ellas eligiesen sus «dayyanim» entre personas expertas conocedoras de la Ley. La renovación de los jueces se haría con una periodicidad anual.

Así mismo, se establece que ningun judío podría acudir con sus pleitos a un tribunal de justicia no judío -fuera real, concejil, señorial o eclesiástico-, excepto por cuestiones económicas Los 
asuntos económicos en general -mamôna' en la terminología jurídica hebrea - son considerados como los más apropiados para ser tratados por los tribunales no judíos: no sólo los relativos a tributación, sino también los que tratan sobre compraventa de bienes muebles e inmuebles, contratos de préstamo y contratos comerciales

En todos los demás casos de la jurisdicción civil es obligado acudir ante un tribunal judío, excepto si el demandante es un hombre violento que no acata la sentencia de este tribunal, en cuyo caso los jueces y el rabino podrían conceder licencia al denunciante a fin de que acudiera a los tribunales ordinarios de justicia.

Pero los tiempos ya no son los del siglo XIII, especialmente después del asunto de Yosef Pichó. A lo largo del siglo XIV había empeorado considerablemente la fama de los jueces judíos, entre los propios miembros de las aljamas. En primer lugar porque, con frecuencia, eran un mero juguete en manos de los hombres poderosos que controlaban la vida de la aljama, y que obligaban a los jueces a hacer en todo su voluntad. Esto dio lugar a bastantes casos de intrigas y atentados contra la vida de los jueces judíos en la Corona de Castilla a lo largo de los siglos XIV y XV. Por otra parte, la actitud de algunos jueces, intransigentes y excesivamente violentos, contribuyó a enturbiar la confianza en la justicia propia de la aljama

Ya con anterioridad, algunos autores habían dejado una puerta abierta a la posibilidad de acudir a tribunales no judíos. Así, rabí Paltoi Gaón considera que es posible para un judío acudir a un tribunal ajeno cuando el demandado se niegue a presentarse ante el tribunal de la aljama y exista peligro de que de este modo escape a la acción de la justicia. Nahmánides de Gerona, en el siglo XIII, defiende el principio de la autonomía judicial judía, pero señala que después de presentar una querella ante el tribunal judío, y con la autorización de éste, podría acudirse a un tribunal no judío ?

Consciente de esta nueva realidad, y del peligro que conllevaba para la autonomía judicial de la comunidad hebrea, Abraham Bienveniste establece graves sanciones espirituales para quienes, incumpliendo las Taqqanot $t$ de 1432, acudan a tribunales no judios: quien desobedeciera sería maldito, sería expulsado de la comunidad y su cuerpo no podría recibir sepultura en cementerio judío.

${ }^{7}$ F. Diaz Esteban, op. cit., pág. 111. 
El capítulo tercero de las Taqqanôt está dedicado a los casos de malsindad y delación, para los que se contempla la pena de muerte. Sin embargo, esto no es sino una declaración de intenciones, pues la decisión última sobre la conveniencia o no del castigo era del Consejo Real.

El último paso legislativo en relación con la autonomía judicial de las aljamas judías se produce a comienzos del reinado de los Reyes Católicos, en las Cortes de Madrigal de 1476. En ellas se vislumbra la decidida voluntad de los monarcas de poner las bases de un importante proceso de reforma judicial y administrativa. La creciente personalidad jurídica de los concejos, perfectamente apreciable en el siglo XV, encontraba en la autonomía judicial de las comunidades judía y mudéjar un importante menoscabo para su jurisdicción, por lo que desde el primer momento los concejos se situaron decididamente entre los que abogaban por la supresión de los privilegios judiciales particulares.

Recogiendo el sentir mayoritario, los reyes confirmaron y renovaron los edictos de 1380 y 1412 en relación con la supresión de la autonomía judicial de los judíos en materia penal, que habían quedado anulados al entrar en vigor las Taqqanôt de 1432. Esta acción de los Reyes Católicos se encontraba en estrecha conexión con las nuevas ideas políticas que sobre el Estado mantenían y defendían los monarcas hispanos, y que les impulsaba a sustraer la jurisdicción penal de las manos de todas las corporaciones políticas particulares ${ }^{8}$. Pese a que estas medidas no llegaran a aplicarse estrictamente, son un claro indicio del evidente cambio de situación.

Por otra parte, y a pesar de las terminantes disposiciones recogidas en las Taqqanót de 1432, a lo largo del siglo XV hubo algunas comunidades hebreas con planteamientos más abiertos en relación con las causas judiciales, llegándose a permitir que si los dos litigantes estaban de acuerdo pudieran acudir a un tribunal de justicia no judío; la única condición es que hubiera al menos dos testigos judíos presentes.

Pero esto no es la norma. En general hubo una resistencia tenaz a que los miembros de las aljamas acudieran a tribunales ajenos, pues suponía una pérdida potencial del control de una importante parcela de la organización comunal. Pero, como tendremos ocasión

B. BAER, op. cit., vol II, págs. 564-565. 
de comprobar, se trata de una batalla perdida, y a fines del siglo XV las justicias real y concejil se imponen claramente a la justicia particular de las aljamas.

Tras esta rápida exposición sobre la evolución general del problema judicial en el conjunto de la comunidad hebrea castellana a lo largo de la Baja Edad Media, seguidamente se analizará el grado de cumplimiento de estas disposiciones y normas de carácter general en un espacio geográfico concreto, como es el formado por las aljamas de las poblaciones de las antiguas diócesis de Calahorra, Osma, Sigüenza y Cartagena, que abarcaban una amplia extensión territorial que comprendía toda la frontera oriental de la Corona de Castilla. El estudio se centra en el último tercio del siglo XV, pues es éste el período cronológico que nos puede ofrecer una imagen más completa del tema en cuestión.

LA JUSTICIA EN LAS ALJAMAS DE LA FRONTERA ORIENTAL DEL REINO DE Castilla

En primer lugar, es preciso señalar que la documentación disponible es escasa para plantear unas conclusiones definitivas sobre este tema, pero sí es suficiente para observar unas tendencias que, en general, coinciden con las que se han señalado anteriormente para el conjunto de la Corona de Castilla.

Así, es fácil apreciar cómo la mayoría de los pleitos y litigios que se plantean entre distintos miembros de la comunidad hebrea se sustancian ante las justicias regia y concejil. De este modo, a fines del siglo XV el papel jugado por los jueces judíos en el seno de las aljamas parece ya muy limitado con relación a períodos anteriores, pese a los denodados esfuerzos que los dirigentes de la comunidad judía y de las aljamas realizaban para asegurar el control de la justicia que, indudablemente, constituía un pilar básico en la organización comunal.

A este respecto, es altamente ilustrativo el caso que se plantea en la aljama murciana a fines de los años ochenta del siglo $\mathrm{XV}$, en relación con la herencia de Salamón Abenturel, quien fue vecino de Murcia.

En julio de 1489 el rey Fernando ordena al bachiller Alvar Pérez de Hiniesta, vecino de Lorca, que investigue acerca del pleito que 
mantenían Ysaque Abenturel y su hijo Yuça con Simuel Abenhayón, judíos de Murcia -en alguna ocasión se indica en la documentación que son vecinos de Lorca-, quienes disputaban en torno a la herencia de Salamón Abenturel, hermano y tío de aquéllos. Salamón Abenturel, personaje de cierta relevancia en la aljama murciana, había fallecido en la ciudad de Vera, a donde se había dirigido con otros judíos murcianos con el fin de tratar ciertas mercancías. El difunto debía de tener algunas deudas o un contrato mercantil suscrito con Simuel Abenhayón, pues los albaceas del testamento indicaron a éste que acudiera a Vera a fin de hacerle entrega de cierta hacienda que había dejado allí Salamón Abenturel y que, según dichos albaceas, le correspondía en parte 9

En noviembre de 1489 el rey Fernando encomienda la resolución de este pleito, así como del que mantenían Ysaque Abenturel y Juan de Benavides acerca de unas deudas que con éste tenía Salamón Abenturel, a Juan Cabrero, corregidor de Murcia y Lorca ${ }^{10}$. Pero tan sólo dos meses después se le encarga este caso a Jorge de Vergara, lugarteniente de corregidor en la ciudad de Lorca, debido a que Juan Cabrero alegó que no podía ocuparse de este asunto por no residir en esta ciudad ".

La resolución del pleito se prolongó largo tiempo, lo que dio lugar a que, entre tanto, Ysaque y Yuça Abenturel acudieran a las justicias de las aljamas de Murcia y Lorca solicitando que determinaran en el pleito. Incluso obtuvieron una carta de don Abraham Seneor, Rabí Mayor de los judíos de Castilla, en la que se prohibía a Simuel Abenhayón acudir a jueces cristianos, so pena de excomunión y de una multa de diez mil maravedíes. Sin embargo la queja de éste no se hizo esperar y, ante el inminente conflicto de jurisdicciones, los Reyes se dirigen en abril de 1492 a las aljamas de los judíos de Murcia y Lorca y les ordenan que se abstengan de juzgar este caso, pues con anterioridad había sido encomendado por ellos a los alcaldes murcianos ${ }^{12}$.

Es interesante observar cómo las autoridades judías - tanto el

9 Archivo General de Simancas (en adelante AGS), Registro General del Sello (en adelante, RGS), fols. 313 y 269 (documentos de julio y agosto de 1489, respectivamente).

10 AGS, RGS, fol. 219 (documento de noviembre de 1489).

" AGS, RGS, fol. 73 (documento de enero de 1490).

12 AGS, RGS, fol. 122 (documento de abril de 1492). 
Rabí Mayor como las justicias de las aljamas de Murcia y Lorcase esfuerzan por la defensa de sus competencias judiciales, de importancia fundamental para el control de las comunidades, según se apuntaba anteriormente. Pero a través del estudio de este asunto concreto puede también apreciarse una cierta desconfianza en algunos judíos hacia la justicia propia de las aljamas que, con frecuencia, se encontraba en las manos de la oligarquía que controlaba el Consejo de la aljama. En este sentido, es significativa la queja de Simuel Abenhayón ante la intervención de las justicias de las aljamas de Murcia y Lorca; no cabe la menor duda de su profunda desconfianza hacia unos jueces que, previsiblemente, sentenciarían en favor de Ysaque y Yuça Abenturel, miembros de una de las familias más afamadas de la aljama murciana, en tanto que la justicia regia aparecía como mucho más imparcial. Por último, es también de destacar la firme postura del Consejo Real negando la intervención de las justicias judías, lo que es una manifestación evidente de la decidida voluntad de ir eliminando paulatinamente las jurisdicciones particulares, como paso fundamental en el proceso de conformación del nuevo Estado.

Así mismo es interesante el caso de Abraham Abadix, vecino de Valencia de Don Juan, quien se vio obligado a acudir ante la justicia regia a causa de la inhibición de los jueces de la aljama de Soria. En efecto, en el año 1487 Abraham Abadix se quejó ante el Consejo Real alegando que poseía unas casas en la judería de Soria, en el castillo, que había recibido de rabí Jaco Gaón, también vecino de Valencia de Don Juan, quien a su vez las había heredado de su padre, pero que no podía tomar posesión de ellas porque las tenía en su poder Çulemán Barchilón, y se negaba a dejarlas libres. Por este motivo había acudido a los jueces de la aljama de Soria, don Abraham Aben Verga y don Ça Bienveniste, quienes le indicaron que no podían hacerle justicia por ser parientes de Çulemán Barchilón. Ante la denuncia de Abraham Abadix, el Consejo Real acordó someter el estudio de esta queja al corregidor y a las justicias de la ciudad de Soria ${ }^{13}$.

Resulta difícil discernir si el documento refleja fielmente la realidad del caso o si, por el contrario, Abraham Abadix acudió por propia iniciativa ante la justicia regia por el temor a una sentencia

${ }^{13}$ AGS, RGS, fol. 40 (documento de junio de 1487). 
contraria a sus intereses; no en vano, su condición de foráneo le ponía en una situación francamente desfavorable ante las justicias de la aljama soriana. Pero, en cualquier caso, lo que resulta evidente es la fragilidad que muestra la justicia particular de la comunidad hebrea, ejemplificada en el caso concreto de la aljama soriana, que a fines del siglo XV era una de las diez aljamas más importantes numéricamente de la Corona de Castilla.

Abundando en este tema, hay otro caso concreto que manifiesta a todas luces la desconfanza que a fines del siglo XV tenían hacia la justicia de la aljama soriana numerosos miembros de ella. En el año 1488 mantenían un enconado pleito los hermanos don Bueno y Symuel Santo, vecinos de Soria y de Burgos, respectivamente, con don Lezar Caballero, vecino de Soria, con motivo de la herencia de la madre de aquéllos, doña Sol. Ésta se había casado en segundas nupcias con don Lezar Caballero quien, con ocasión de su matrimonio, había recibido en dote grandes cantidades de maravedíes. Pero, además, era también con anterioridad tutor de los hermanos Bueno y Symuel Santo, y aprovechando esta circunstancia se había hecho con la posesión de toda la hacienda perteneciente a éstos. Los problemas surgieron al morir doña Sol, entablándose una árdua disputa en torno a su herencia entre sus hijos y su segundo marido. La pugna debió alcanzar tal magnitud que intervino, incluso, don Abraham Bienveniste, Rabí Mayor de los judíos de Castilla, quien ordenó que el asunto se pusiera en manos de un juez árbitro. Este juez - judío, sin duda alguna - resolvió el pleito ordenando a don Lezar que pagara a sus hijastros una cantidad total de cuatrocientos veinticinco mil maravedíes, de los que tan sólo les hizo entrega de cien mil, negándose a pagar la cantidad restante. Mientras todo esto ocurría, se produjo el fallecimiento de don Lezar, quien dejó todos sus bienes a su nueva mujer, Daza, con quien pleiteaban los hermanos don Bueno y Symuel. Pero temiendo que no podrían obtener una sentencia favorable de las justicias judías de Soria, debido a que la parte contraria eran personas afamadas y muy favorecidas en esta ciudad, según se indica textualmente en la documentación, se quejaron ante el Consejo Real, que comisionó al corregidor de Soria y al licenciado Caldero, Alcalde de Casa y Corte, para que vieran este pleito y determinaran en él según justicia ${ }^{14}$.

14 AGS, RGS, fol. 154 (documento de abril de 1488). 
Por otra parte, a finales del siglo XV la obediencia y el respeto de los judíos hacia los jueces de las aljamas no eran los mismos que en el siglo XIII, de forma que no son raras las referencias documentales a desobediencias pertinaces a sentencias dictadas por jueces judíos o, incluso, a agresiones físicas contra ellos.

Éste es el caso de rabí Ospina, juez de la aljama de Miranda de Ebro (Burgos) quien un día, al salir de la oración comunitaria en la sinagoga, fue agredido con un cuchillo por Abraham Habillo, vecino de dicha población, quedando malherido. La causa de esta agresión había sido la excomunión que el juez dictó contra el agresor, por motivos que desconocemos. Como autor de este delito, Abraham Habillo fue condenado por la justicia regia a la pena de muerte -en causas criminales no podían intervenir los jueces judíos-, pero como quiera que la aplicación de la sentencia se dilataba en exceso, rabí Ospina reclamó de los reyes su inmediato cumplimiento ${ }^{15}$.

Así mismo, la documentación nos ofrece alguna noticia sobre la actuación de las justicias de la aljama judía de Haro a fines del siglo XV. En el año 1488 estaba preso rabí Arón, vecino de esta ciudad, a quien retenía el mayordomo de los judíos por ciertas causas que no se especifican. Otro judío de Haro, Bellido Alanate, se comprometió a pagar los dos mil maravedies de fianza que solicitaba el mayordomo, así como las costas del proceso judicial. En seguimiento de este acuerdo comparecieron ante el alcalde y regidores del concejo el mayordomo de la aljama, por una parte, y los dayanes, por la otra. Da la impresión de que se trata de una causa que competía a los propios jueces de la aljama - probablemente una deuda-, pero lo cierto es que nada seguro se puede afirmar al respecto debido a la exigua información facilitada por la documentación ${ }^{16}$.

Pero éstas son todas las noticias que hemos encontrado acerca de la actuación de las justicias judías en las aljamas del área de estudio. En todas las demás causas - tanto civiles como criminalesactúan las justicias regia o concejil.

15 AGS, RGS, fol. 180 (documento de junio de 1483). Véase F. Cantera Burgos, "La judería de Miranda de Ebro", Sefarad I (1941) 89-140 y II (1942) 325-375, 360361, y F. BAER, Die Juden im Christlichen Spanien, I/2: Kastilien/Inquisitionakten, Berlín 1929, págs. 349-350.

16 Archivo Municipal de Haro, Actas Municipales, legajo 57, letra Z. Véase E. Cantera Montenegro, Las juderias de la dibcesis de Calahorra en la Baja Edad Media, Logrơ̂o 1986, pág. 399. 
Algunas de estas causas competen propiamente a la justicia regia, pues se trata de casos que caen dentro de la jurisdicción criminal, como agresiones físicas o violaciones.

En marzo de 1480 los Alcaldes de Casa y Corte ordenaron ejecutar una sentencia dada contra Isaque Abotín, judío morador en Murcia, como reo de las heridas producidas a Isaque Abenacoje en cierto "alboroto" que se había producido en la judería murciana ${ }^{17}$.

En noviembre de 1489 el rey Fernando ordena a las autoridades y justicias de la ciudad de Murcia que investiguen la denuncia presentada por doña Adonça, vecina de Murcia, contra Mose Abenturiel, vecino de la misma ciudad, a quien acusaba de haber forzado a una hija suya, doncella, y que si hallaban que era cierta la acusación que lo prendieran y actuaran según justicia ${ }^{18}$.

Así mismo, son tratados por la justicia regia otros casos de agresión física, como el que pendía entre Abraham Trigo y Abraham Alfajo, judíos de Zaragoza y Logroño, respectivamente, acusado éste de haber agredido a aquél con un cuchillo 19; o aquél otro en el que rabí Ça, vecino de Logroño, acusaba de agresión a rabí Jaco Galochero, vecino de la misma ciudad y médico de profesión ${ }^{20}$.

Pero además de estas causas criminales, a fines del siglo XV se debatían también ante las justicias regia y concejil otros diversos casos que caían dentro de la jurisdicción civil -pleitos por herencias, enfrentamientos familiares-, y que por su materia eran, en principio, de competencia de los tribunales de justicia de la aljama.

En el año 1491 Simuel Abancar, judío de Nájera, mantenía un pleito con sus suegros, don Çaçón Habaz y Soloro, vecinos de San Millán de la Cogolla, a quienes acusaba de que en su ausencia le habían robado numerosos bienes de su casa, así como de haber obligado a su mujer Vellida a abandonarle ${ }^{21}$. Es posible que el abandono del domicilio conyugal por parte de Vellida esté en relación con la denuncia que por las mismas fechas se tramitaba ante la justicia regia contra Simuel Abancar, quien había sido acusado de

17 AGS, RGS, fol. 166 (documento de marzo de 1480).

18 AGS, RGS, fol. 239 (documento de noviembre de 1489).

19 AGS, RGS, fol. 58 (documento de noviembre de 1485). Véase, E. CanTERA Montenegro, op. cit., pág. 500.

20 AGS, RGS, fol. 251 (documento de julio de 1489). Véase E. CanTera MONTENEGRO, op. cit., pág. 502.

21 AGS, RGS, fol. 91 (documento de mayo de 1491). 
un intento de violación en la persona de la mujer de Juan Pérez, vecino de San Millán de la Cogolla ${ }^{22}$.

Lo realmente significativo para nuestro estudio es que el primero de estos casos no se tramitara ante las justicias judías, pues 'se trata de un asunto que cae plenamente dentro de sus competencias. Es muy posible que Simuel Abancar, quien actúa como parte demandante, no acudiera ante las justicias judías, debido a la más que probable interrelación de este caso con el intento de violación antes mencionado, con lo que su culpabilidad sería manifiesta. Pero es también posible que las juderías de Nájera y de San Millán de la Cogolla no contaran ya con jueces propios - dada la escasa importancia numérica de estas comunidades-, y que antes que acudir a los jueces de una aljama próxima - Haro, Logroño- prefiriera presentar la denuncia ante la justicia regia.

Es indudable que, con el paso del tiempo, los judíos castellanos confian más en las justicias regia y concejil que en las justicias propias para dilucidar sus asuntos internos $y$, contraviniendo las instrucciones de los dirigentes de la comunidad hebrea, acuden a aquéllas para resolver asuntos y contenciosos que tradicionalmente habían sido de competencia de los tribunales particulares de las aljamas. Éstos son, fundamentamlente, los pleitos por herencias, de los que hay varios ejemplos concretos.

En agosto de 1491 el Consejo Real ordena a Ysaque Alemán, vecino de la localidad logroñesa de Arenzana de Yuso, que devuelva a Yuçe y a Mose Abenazara, vecinos de Belorado y de unos veinte años de edad, los bienes de sus padres Ysaque Abenaza y Rica Juda, ya difuntos, que podían valer unos cien mil maravedíes, y de los que se había apropiado Ysaque Alemán al contraer matrimonio, en segundas nupcias, con Rica Juda ${ }^{23}$.

Otro pleito de carácter familiar es el que se plantea un año antes, en 1490, entre Yuda Açerol y su mujer Clara, vecinos de Soria. Según se indica en el documento, el conocimiento de este pleito correspondía al corregidor y a los alcaldes de la ciudad de Soria, quienes no emitían la sentencia correspondiente a pesar de que ya hacía más de cincuenta días que el pleito había quedado concluso. Ante la queja de los litigantes, el Consejo Real ordena al

22 AGS, RGS, fol. 57 (documento de junio de 1491).

23 AGS, RGS, fol. 262 (documento de agosto de 1491). 
corregidor y a los alcaldes antedichos que otorguen sentencia interlocutoria en el plazo de seis días, y definitiva dentro de los veinte días siguientes ${ }^{24}$.

Pese a que la documentación no hace ninguna referencia a las causas concretas de este pleito, todo hace pensar que se trata de un asunto relacionado con los bienes aportados al matrimonio en dote o en arras.

Por último, la documentación nos ofrece también algunas noticias sobre otros pleitos entre miembros de distintas comunidades judías por cuestiones de carácter económico y que, según es ya norma en el siglo $\mathrm{XV}$, son vistos y sentenciados por las justicias regias $\mathrm{o}$ concejiles.

En octubre de 1491, el Consejo Real ordena a las autoridades concejiles de Llerena que vean el pleito que estaba pendiente entre Israel, judío vecino de esta población, y Mayr Abenafo, vecino de Murcia, con ocasión de ciertas cantidades de maravedíes que aquél debía a éste por un contrato en el que el judío murciano figuraba como fiador ${ }^{25}$.

Por las mismas fechas mantenían una pendencia doña Vellida y Una, mujer ésta de Levi, vidriero, y vecinas ambas de Aranda de Duero, con motivo de unos bienes que ésta había recibido de doña Vellida en guarda y que se negaba a devolverle. Los alcaldes ordinarios de Aranda de Duero habían dictaminado en contra de la reclamación de doña Vellida, por lo que ésta acudió en grado de apelación ante la justicia regia ${ }^{26}$.

Así mismo, el Consejo Real comisionó al corregidor de Soria la resolución del pleito que en octubre de 1491 mantenía Alegre, judío de esta ciudad, con don Symuel Abenamias y Yuçe el Roxo, también judíos sorianos, con ocasión de un contrato no resuelto. Alegre figuraba como fiador en una operación de compra de cien cueros vacunos por parte de los otros dos judíos, quienes no pagaron las cantidades convenidas en los plazos fijados en el contrato. Por este motivo, Ínigo de Torres, mercader vecino de Valladolid, quería ejecutar el contrato en el fiador. Ante la queja de Alegre, las justicias regias ordenan que el contrato se ejecute en los bienes de

24 AGS, RGS, fol. 472 (documento de marzo de 1490).

25 AGS, RGS, fol. 98 (documento de octubre de 1491).

26 AGS, RGS, fol. 114 (documento de noviembre de 1491). 
don Symuel Abenamias y de Yuçe el Roxo ${ }^{27}$. Don Symuel Abenamias es un personaje importante en la aljama soriana, actuando como representante de la misma en la súplica que en marzo de 1491 se hace ante los Reyes Católicos para que los repartos de los tributos que se hacían en la aljama fueran más justos, y que se pagaran con arreglo a los bienes que poseía cada uno ${ }^{28}$. Es posible que esta circunstancia influyera en la decisión de Alegre de acudir ante la justicia regia en solicitud de favor, rechazando la posibilidad de acudir ante los jueces de la aljama, por el temor a que éstos se dejaran influir por la personalidad de la otra parte.

Por último, son interesantes ciertas informaciones que nos ofrece la documentación en relación con los pleitos que mantenían diversos judíos de Haro, por cuestiones de carácter económico. En agosto de 1489 tenían ciertas diferencias don Jaco el Cohén, mayordomo del duque del Infantado, y Yuda Cobo, hijo de don Mose Cobo y yerno de Jachón Faras, mayordomo del adelantado don Íñigo de Guevara, por las albaquías pertenecientes al duque del Infantado, de las que don Jaco tenía arrendada la cuarta parte entre los años 1479 y 1486.

Es muy probable que este pleito se sustanciara ante los jueces del duque del Infantado, pues por las mismas fechas se encargaban éstos de dar por conclusa la disputa que mantenían Yuda Cobo y don Jaco de Salinillas, vecino éste de la población alavesa de Berantevilla, por cierta deuda que éste tenía con aquél. Los jueces del duque son en este caso el bachiller Diego de Medina y don Semuel Asayol, judío vecino de Haro ${ }^{29}$. A este respecto, cabe suponer que debió de ser hasta cierto punto frecuente la intervención de algún miembro destacado de las aljamas, generalmente un dayán, junto a los jueces reales, concejiles y sefforiales cuando éstos eran los encargados de resolver asuntos internos entre judíos. Así, no es otro el papel que juega don Semuel Asayol, pues es impensable que este personaje actuara como juez en pleitos en los que interviniera algún cristiano, que serían siempre vistos por jueces cristianos.

${ }^{27}$ AGS, RGS, fols. 177, 109 y 87 (documentos de marzo de 1489, octubre de 1491 y octubre de 1491, respectivamente).

${ }^{28}$ AGS, RGS, fol. 415 (documento de marzo de 1491).

${ }^{29}$ Biblioteca Nacional, Manuscritos, 627, fols. 5, 6 y 26. 
CONCLUSIÓN

A modo de muy rápida conclusión, puede afirmarse que el estudio de la documentación disponible confirma plenamente las hipótesis generales señaladas al comienzo de este trabajo para el conjunto de la Corona de Castilla.

A fines del siglo XV las principales aljamas de nuestra área concreta de estudio - Haro, Miranda de Ebro, Soria, Murciacuentan con dayanes o jueces propios encargados de sentenciar en las causas internas entre miembros de la minoría hebrea; a ellos habrían de acudir los judíos de la aljama y los que residían en poblaciones próximas que no llegaban a constituir aljama.

Además, es fácil apreciar el esfuerzo de los dirigentes locales judíos, y aún incluso del propio Rabí Mayor de la Corona de Castilla, don Abraham Seneor, en orden a asegurar el control de la justicia en el seno de las aljamas, como una de las principales garantías para el mantenimiento de la independencia y de la cohesión interna de la comunidad judía.

Pero la situación ha cambiado ya sustancialmente con relación al siglo XIII. A fines del siglo XV no sólo las causas criminales y los pleitos por motivos económicos, sino también con mucha frecuencia otros diversos pleitos familiares eran tratados ante las justicias regia y concejil, haciendo caso omiso de las recomendaciones de las autoridades judías de acudir siempre ante los jueces de las aljamas. La causa de este cambio de actitud parece radicar en una fuerte suspicacia de los judíos más desfavorecidos, económica y socialmente, hacia los jueces de las aljamas, por considerar que con demasiada frecuencia éstos estaban sometidos a las presiones de las familias más poderosas. Frente a ellos, juzgaban a la justicia regia mucho más imparcial por su lejanía respecto de los asuntos ${ }^{30}$.

Esta evolución del problema de la justicia en el seno de la comunidad judía confluye en el tiempo con la decidida voluntad del

${ }^{30}$ Mayores recelos despertaban entre los judios las justicias concejiles pues, por su proximidad al medio geográfico y a los protagonistas de los conflictos, eran mucho más influenciables.

Buen ejemplo de esto es el caso de Salamón Levi, judío de Haro, quien solicitaba la intervención de las justicias regias en el pleito que mantenía con Bertol Sánchez, vecino de Logroño, pues desconfiaba de los jueces y de los regidores de esta ciudad debido a que Bertol Sánchez era un hombre de influencias y él no era sino "un judío e pobre». (AGS, RGS, fol. 195, documento de diciembre de 1489). 
Consejo Real de poner fin a cualquier atisbo de autonomía judicial que pusiera, o pudiera poner, cortapisas al nuevo modelo de Estado que se proyectaba, y en el que una Justicia única constituía uno de sus pilares básicos. Como hemos tenido ocasión de comprobar, pese al reconocimiento de los jueces judíos para sentenciar en causas civiles, hay casos concretos en los que el Consejo Real les ordena que se abstengan de intervenir, a pesar de que el asunto fuera de su estricta competencia.

El análisis de este tema concreto nos permite vislumbrar, en definitiva, la paulatina disgregación interna que sufría ya la comunidad hebrea castellana a fines del siglo $\mathrm{XV}$, así como el creciente proceso de unitarismo político, religioso y administrativo que impulsan los monarcas castellanos desde el acceso al trono de la dinastía Trastámara - sus principales valedores serán los Reyes Católicos-, y que en relación con la minoría judía se materializará, finalmente, en la promulgación del edicto de expulsión general del 31 de marzo de 1492.

\section{RESUMEN}

En este trabajo se aborda el estudio del mantenimiento del principio de la autonomía judicial en las aljamas judías de las comarcas más orientales de la Corona de Castilla a fines de la Edad Media. En contraste con el siglo XIII, puede apreciarse un paulatino retroceso en la capacidad de actuación de los jueces judíos, lo que obedece a una doble motivación: al decidido empeño de la autoridad monárquica de terminar con cualquier manifestación de autonomía judicial, como paso fundamental en la construcción del nuevo Estado, y a la propia desconfianza de los judíos hacia unos jueces demasiado sometidos a las presiones de las familias más poderosas de las aljamas.

\section{SUMMARY}

This paper examines the way in which the principle of judicial autonomy was maintained in the Jewish communities of the easternmost areas of the Crown of Castile towards the end of the middle ages. In contrast to the 13th century, a gradual recession was seen in the Jewish Judges' capacity to act. This was for two reasons: firstly, the monarchic authority's determination to put an end to any expression of judicial autonomy, as a fundamental step towards the construction of the new State; and, secondly, the Jews' own mistrust of judges who were far too subject to pressure from the most prowerful families in the Jewish community. 